\title{
Anecdotes in animal behaviour
}

"It is just an anecdote", is an often-heard critique to scientists describing animal behaviour that has not been reported before. But what if this anecdote is a qualitative, rich observation, showing a truly unique behaviour or event that can change the way we think about a species? If an ethologist or another animal expert observes unforeseen behaviour that may be of interest, it is a loss for the field if this observation remains unreported and as a result forgotten. This is especially the case for very rare behaviours or unusual circumstances under which certain behaviours occur.

In the past, anecdotal accounts have brought behaviours such as hunting, tool use, infanticide and tactical deception (these examples concern primates) to our attention, and have motivated researchers to study these behaviours quantitatively. Nowadays, such narrative accounts of unique behaviours are on a stark decline (Ramsay \& Teichroeb, 2019).

In order to safeguard valuable anecdotes in animal behaviour and prevent them from oblivion, at Behaviour, we deem it highly valuable to make them available again to the scientific community, and predict that by doing so, readers might recognize the behaviour that is described and, ideally, reply to these in a 'commentary / reflection'. This will help to contextualize the anecdote better, recognize its scope and generality, and stimulate the design of new directions of study based upon these anecdotes. Eventually, the initial report of a certain anecdote could, together with commentaries and more evidence, become a collection centred around a certain topic (for example: "Tactical deception in primates" (Whiten \& Byrne, 1988)).

We hereby invite scholars who have anecdotal evidence of unique behaviour in any species, to submit these as a commentary to Behaviour, and if possible, accompanied by a video or photograph. The narrative will be re- 
viewed as usual, by experts in the field so that only well-supported, relevant anecdotes will be published.

Mariska E. Kret and Tom S. Roth

Editors

\section{References}

Ramsay, M.S. \& Teichroeb, J.A. (2019). Anecdotes in primatology: temporal trends, anthropocentrism, and hierarchies of knowledge. - Am. Anthropol. 121: 680-693.

Whiten, A. \& Byrne, R.W. (1988). Tactical deception in primates. - Behav. Brain Sci. 11: 233-244.

\section{To submit an anecdote:}

Article type: The text should be submitted as a 'Commentary / Reflection' through the Editorial Manager submission system at https://www. editorialmanager.com/beh/Default.aspx.

Words per paper: 2000 words, excl. references (this is directive, deviations are allowed).

Publication fee: Please note that the open access fee for papers on anecdotes is lower: $1-4$ pages, $33 \%$ of the article processing charge; $5-7$ pages, $66 \%$ of the price; $8+$ pages, the full price. All details of pricing are available online by following this link: https://brill.com/page/oacharges.

Deadline: There is no submission deadline. This is a try-out that we would like to continue if successful. 